\title{
POLA KOMUNIKASI KESEHATAN MASYARAKAT PEDESAAN DI JAWA TIMUR
}

\author{
Tatag Handaka ${ }^{1}$, Dessy Trisilowaty ${ }^{2}$, dan Hetti Mulyaningsih ${ }^{3}$ \\ ${ }^{1,2}$ Staf Pengajar Jurusan Ilmu Komunikasi, Fakultas Ilmu Sosial dan Ilmu Budaya-Universitas Trunojoyo Madura \\ ${ }^{3}$ Staf Pengajar Jurusan Sosiologi Fakultas Ilmu Sosial dan Ilmu Budaya-Universitas Trunojoyo Madura \\ E-mail: tatag_h@yahoo.com; dessy.t@hotmail.com; hetti.mulyaningsih@gmail.com
}

\begin{abstract}
ABSTRAK. Pemahaman dan kesadaran masyarakat tentang kesehatan di pedesaan Jawa Timur masih rendah, khususnya kesehatan jamban/kakus. Hal ini ditunjukkan dengan jumlah fasilitas jamban/kakus tidak sehat (unimproved) yang masih banyak. Pemerintah Daerah melalui Dinas Kesehatan dan Puskesmas sudah melakukan berbagai strategi komunikasi untuk menyampaikan pesan kesehatan. Promosi kesehatan ini dilakukan oleh petugas Puskesmas melalui komunikasi antar personal, komunikasi kelompok dan komunikasi massa. Penelitian tentang pola komunikasi ini dapat dijadikan dasar bagi institusi kesehatan (Dinkes/Puskesmas) untuk menyampaikan pesan kesehatan agar lebih efektif. Tujuan penelitian ini adalah untuk mengetahui pola komunikasi kesehatan masyarakat pedesaan di Jawa Timur. Teori yang digunakan adalah teori komunikasi kesehatan. Metode penelitian yang digunakan adalah studi kasus eksploratif dengan paradigma konstruktivisme (constructivism paradigm). Paradigma dan metode ini digunakan untuk menemukan pemahaman individu atas realitas sosial yang mereka hadapi dalam kehidupan sehari-hari (socially meaningful action). Temuan penelitian menunjukkan bahwa pola komunikasi antar personal petugas Puskesmas dengan penduduk biasanya dilakukan di rumah, Posyandu dan PKK. Pola komunikasi kelompok dilakukan petugas Puskesmas dengan penduduk di pertemuan PKK, Posyandu, pengajian, tahlilan, istighasah dan warung kopi. Pola komunikasi massa lebih banyak dilakukan melalui media radio, poster, pamflet, brosur, leaflet, buku dan media pertunjukkan tradisional (ludruk dan tayub). Kesimpulan penelitian adalah Dinkes/Puskesmas bisa menggunakan pola komunikasi secara terpisah, tapi bisa juga semua pola komunikasi diintegrasikan untuk menyampaikan pesan kesehatan.
\end{abstract}

Kata kunci: pola komunikasi kesehatan, promosi kesehatan, masyarakat pedesaan

\section{HEALTH COMMUNICATION PATTERN OF RURAL COMMUNITY IN EAST JAVA}

\begin{abstract}
Awareness of health sanitation in rural East Java was still low, especially health latrine. This was indicated by the number of unsanitary latrines which were still many. Local government through Public Health Office has done a variety of communication strategies to convey health messages. Research about communication patterns could be used as the basic for health institution (Public Health Office /Public Health Center) to deliver health messages to become more effective. The research method used explorative case study with constructivism paradigm. Paradigm and this method were used to find an individual's comprehension of social reality which were they found in daily life. The result showed that the pattern of interpersonal communication was conducted by Puskesmas with society who were at home, Posyandu and PKK. The pattern of group communication was conducted by Puskesmas workers with society at PKK, Posyandu, pengajian, tahlilan, istighasah and coffee shop. The pattern of mass communication was mostly done through the media such as radio, posters, pamphlets, brochures, leaflets, books and traditional entertainment media (ludruk and tayub). Conclusion of the study was Public Health Office and Puskesmas could use communication patterns individually, but also could use all communication patterns which were integrated to convey health messages.
\end{abstract}

Key words: patterns of health communication, health promotion, rural communities

\section{PENDAHULUAN}

Salah satu aspek kesehatan masyarakat adalah kesehatan jamban/kakus. Kesehatan jamban/kakus masih belum mendapat perhatian yang baik dari masyarakat pedesaan di Jawa Timur, khususnya di Kabupaten Gresik, Lamongan dan Bojonegoro. Meskipun Pemerintah Daerah sudah berusaha untuk memberikan program komunikasi kesehatan melalui Dinas Kesehatan (Bagian Promosi Kesehatan/Promkes dan Kesehatan Lingkungan/ Kesling) serta Puskesmas, namun masih cukup banyak ditemukan jamban/kakus tidak sehat di ketiga wilayah itu.

Dinkes dan Puskesmas sudah menyampaikan pesan kesehatan melalui berbagai macam pola komunikasi ke masyarakat pedesaan. Namun belum semua pesan kesehatan itu sampai ke masyarakat. Media kesehatan yang dibuat Dinkes dan Puskesmas masih banyak yang belum sampai ke kader PKK/Posyandu dan masyarakat.

Dinkes dan Puskesmas perlu memahami pola komunikasi kesehatan yang telah dilakukan. Pengetahuan dan pemahaman pola komunikasi ini penting agar pesan kesehatan bisa sampai ke seluruh penduduk. Pola komunikasi kesehatan sering berkaitan dengan jenis kelamin, usia, pendidikan, pekerjaan, kelas sosial, dan budaya masyarakat.

Hasil penelitian Water and Sanitation Program World Bank (WSP-World Bank) tahun 2010 di pedesaan Jawa Timur menunjukkan bahwa pemahaman dan kesadaran masyarakat pedesaan masih rendah terhadap aspek kesehatan tersebut. Sebagian masyarakat pedesaan di ketiga wilayah tersebut yang menjadi populasi penelitian, masih belum menganggap kesehatan jamban/kakus sebagai suatu bagian perilaku hidup yang penting.

Kesehatan jamban/kakus harus dikomunikasikan 
kepada masyarakat, agar masyarakat mendapat pemahaman dan kesadaran tentang arti pentingnya. Pesanpesan tentang kesehatan tersebut bisa dikomunikasikan melalui berbagai macam konteks. Bisa melalui konteks komunikasi antar personal, komunikasi kelompok atau komunikasi massa.

Data masyarakat pedesaan Jawa Timur yang memiliki fasilitas kakus/jamban tidak sehat (unimproved) bisa dilihat dalam tabel berikut :

Tabel 1. Jumlah Jamban/ Kakus Tidak Sehat (Unimproved)

\begin{tabular}{|c|c|c|c|c|}
\hline No & Kabupaten & Kecamatan & Desa & $\begin{array}{c}\text { Jamban/ } \\
\text { Kakus } \\
\text { Unimproved }\end{array}$ \\
\hline \multirow{4}{*}{1} & \multirow{4}{*}{ Bojonegoro } & Kapas & Bakalan & 305 \\
\hline & & Gondang & Pajeng & 282 \\
\hline & & \multirow{2}{*}{ Temayang } & Papringan & 153 \\
\hline & & & Jono & 175 \\
\hline \multirow{5}{*}{2} & \multirow{5}{*}{ Gresik } & \multirow{5}{*}{$\begin{array}{l}\text { Wringin } \\
\text { Anom }\end{array}$} & $\begin{array}{c}\text { Kesamben } \\
\text { Kulon }\end{array}$ & 557 \\
\hline & & & Pedagangan & 405 \\
\hline & & & Sumengko & 209 \\
\hline & & & $\begin{array}{l}\text { Kepuh } \\
\text { Klagen }\end{array}$ & 348 \\
\hline & & & Sembung & 530 \\
\hline \multirow{3}{*}{3} & \multirow{3}{*}{ Lamongan } & Modo & Modo & 71 \\
\hline & & Turi & Ngujungrejo & 239 \\
\hline & & $\begin{array}{c}\text { Karang } \\
\text { binangun }\end{array}$ & $\begin{array}{c}\text { Karang } \\
\text { binangun }\end{array}$ & 81 \\
\hline
\end{tabular}

Sumber diolah dari: WSP-World Bank (2010)

Jumlah total jamban/ kakus tidak sehat (unimproved) di Kabupaten Bojonegoro ada 1.296 buah, di Kabupaten Lamongan ada 777 buah dan di Kabupaten Gresik 5.640 buah. Data ini bisa dijadikan sebagai salah satu indikator untuk mengetahui tingkat pemahaman dan kesadaran masyarakat tentang kesehatan kakus/jamban yang masih rendah tadi.

Penelitian ini menggunakan teori komunikasi kesehatan (health communication). Komunikasi kesehatan meliputi unsur-unsur komunikator kesehatan, komunikan, pesan, media, efek, dan konteks komunikasi kesehatan; (Liliweri, 2009: 163). Adapun konteks komunikasi kesehatan dapat disebutkan sebagai berikut :

\section{Komunikasi Antar Pribadi}

Teori komunikasi antar pribadi yang digunakan dalam penelitian ini adalah symbolic interactionism. Blumer menyatakan bahwa ada tiga prinsip dasar dalam teori interaksionisme simbolik yaitu: meaning, language, dan thought. Ia mengatakan bahwa meaning adalah ketika manusia bertindak atau menyikapi orang/ sesuatu berdasarkan makna yang mereka pahami dari individu atau sesuatu tersebut, dapat dilihat di Monthly, 2010.

Premis yang kedua yaitu language, maksudnya makna yang muncul atau dapat diketahui dalam interaksi sosial antara individu dengan individu yang lain.
Makna dinegosiasikan melalui penggunaan bahasa. Sedang premis yang ketiga adalah thought, yaitu sebuah interpretasi individu atas simbol dimodifikasi melalui proses pemikirannya sendiri. Interaksionisme simbolik menggambarkan pemikiran sebagai sebuah percakapan dengan dirinya sendiri (inner conversation/ dialogue), Mead menyebut hal ini sebagai pemikiran (minding) (Griffin, 2006: 56-60).

2. Komunikasi Kelompok

Teori komunikasi kelompok yang digunakan dalam penelitian ini adalah Groupthink Theory (teori pikiran kelompok). Hipotesis dalam groupthink dikembangkan Janis dari pengujian secara detil tentang efektifitas pembuatan keputusan kelompok. Konsep penting dalam teori ini adalah kohesivitas (cohesiveness), yaitu tingkat saling pemahaman antar individu yang menjadi anggota kelompok. Semakin tinggi tingkat kohesivitas kelompok, maka semakin tinggi pula tingkat tekanan (pressure) kelompok pada individu yang menjadi anggota kelompok tersebut (Littlejohn \& Foss, 2008: 241-243).

3. Komunikasi Massa

Teori komunikasi massa yang digunakan dalam penelitian ini adalah Cultivation Theory. Menurut teori ini, televisi/media adalah tempat sentral dalam kehidupan sehari-hari masyarakat, ia mendominasi lingkungan simbolik kita, menggantikan pesan tentang realitas untuk pengalaman personal dan makna lain tentang dunia (McQuails, 2000: 283). Televisi/media sebagai lingkungan simbolik tempat dimana kita tinggal, sebuah lingkungan yang mengultivasi cara pandang secara spesifik (McQuails, 2002: 251).

\section{METODE}

Penelitian ini menggunakan paradigma konstruktivisme (constructivism paradigm). Asumsi-asumsi paradigma konstruktivisme adalah segala tindakan manusia merupakan bentuk komunikasi; budaya dalam komunikasi mencerminkan realitas-realitas yang dihayati bersama dan bagaimana realitas-realitas tersebut membentuk peristiwa-peristiwa tertentu (Neuman, 2000: 115).

Metode penelitian yang digunakan studi kasus eksploratif, menitikberatkan pada observasi dan suasana alamiah (naturalistics setting). Peneliti bertindak sebagai pengamat. Ia membuat kategori perilaku, mengamati gejala, dan mencatatnya dalam buku observasi. Metode case study untuk analisis kualitatif merujuk pada cara spesifik koleksi, organisasi dan analisa data, dalam pengertian merepresentasikan sebuah proses analisis. Tujuannya adalah untuk mendapatkan informasi komprehensif, sistematis dan mendalam tentang tiap kasus yang diteliti (Patton, 2002: 447).

Penelitian kualitatif mendasarkan diri pada aspek reflective. Dimana kedudukan suatu penelitian bersifat 
meggali interpretasi subyek. (Lindlof, 1995: 296). Aspek yang lebih penting adalah dapat mencerminkan sifat-sifat realitas lebih tepat, pemahaman yang benar/ otentik tentang aspek budaya yang diteliti (Denzin \& Lincoln, 2000: 374).

Hubungan teori/konsep dengan data empirik bersifat exploratory, teori dimunculkan atas data empirik. Sifat exploratory juga berarti hubungan teori dan data memberikan pengertian yang mendalam, kemampuan untuk memahami secara komprehensif mengenai situasi masalah penelitian (Malhotra, 1999: 293).

\section{HASIL DAN PEMBAHASAN}

Masyarakat pedesaan yang belum memiliki jamban/kakus sehat (improved), masih banyak melakukan buang air besar di sungai atau jamban yang digali di kebun. Kondisi ini tentu sangat berpotensi bagi munculnya bermacam penyakit, seperti : diare, demam berdarah dengue (DBD), penyakit kulit, kolera, disentri dan lain-lain.

Salah satu usaha Dinas Kesehatan/Dinkes untuk menghadapi persoalan ini adalah dengan melakukan komunikasi kesehatan pada masyarakat. Komunikasi kesehatan telah dilakukan Dinkes (Promkes/Kesling) melalui Puskesmas yang berada di wilayahnya. Pesan komunikasi yang disampaikan oleh Dinkes ke Puskesmas selain kesehatan jamban/kakus, juga meliputi kesehatan lingkungan, air bersih, bahaya rokok, kesehatan ibu dan anak, penyakit menular, edukasi gizi, cuci tangan pakai sabun (CTPS) dan program kesehatan lainnya.

Dinkes secara teratur melakukan komunikasi dengan Puskesmas di daerahnya, hal ini dilakukan agar ada kesinambungan pesan kesehatan. Puskesmas kemudian melanjutkan pesan kesehatan ke Desa-desa, dan dari Desa dikomunikasikan ke masyarakat. Proses komunikasi kesehatan ini memiliki beberapa konteks, yaitu :

\section{Komunikasi Antar Personal}

Komunikasi antar personal antara petugas Puskesmas dengan Ibu-Ibu lebih banyak dilakukan di keluarga. Petugas Puskesmas secara rutin mengunjungi Ibu-Ibu di rumah masing-masing. Keluarga merupakan tempat dimana komunikasi antar personal paling banyak dilakukan oleh petugas Puskesmas dan masyarakat. Selain itu, komunikasi antar personal juga dilakukan saat pertemuan Posyandu dan PKK.

Kegiatan Posyandu dan PKK sudah terjadwal dengan baik di tiap-tiap Desa/RT. Misalnya di desa Kepuh Klagen (Gresik), Posyandu sudah dibagi ke Dusun, pelaksana Posyandu dikelola masing-masing Dusun dan dilakukan secara bergiliran pada tengah bulan. Demikian juga di Desa Ngujungrejo (Lamongan) dan Desa Bakalan (Bojonegoro), Posyandu dan kegiatan PKK dilakukan secara teratur oleh Ibu-Ibu dan biasanya dilakukan di
Balai Desa. Petugas Puskesmas memberikan konseling untuk Ibu-Ibu tentang berbagai persoalan kesehatan dalam kesempatan seperti ini. Baik pesan kesehatan tentang jamban/kakus, pembiasaan cuci tangan pakai sabun, buang air di wc, bahaya merokok maupun edukasi gizi. Pola komunikasi antar personal dapat digambarkan dalam bagan berikut:

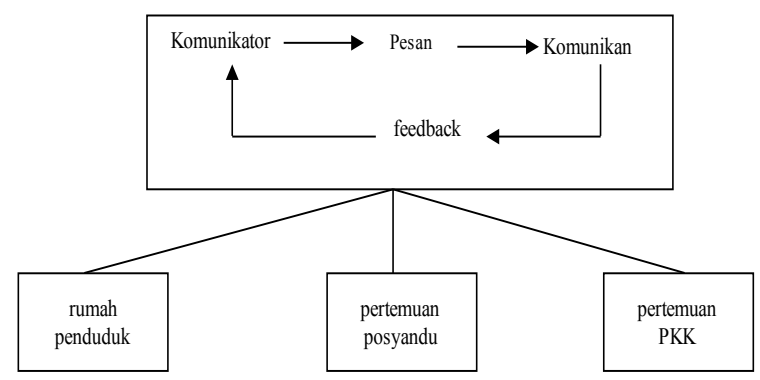

Gambar 1. Pola Komunikasi Antar Personal

Makna (meaning) kesehatan menjadi penting dalam komunikasi antara petugas kesehatan dan IbuIbu karena disampaikan secara personal. Ibu-Ibu bisa lebih leluasa menanyakan berbagai persoalan terkait masalah kesehatan. Petugas kesehatan juga bisa lebih intens memberikan penjelasan karena kedekatan antara komunikator dan komunikan dalam pola komunikasi ini.

Pikiran (thought) dari Ibu-Ibu juga bisa lebih cepat terbentuk karena intensitas komunikasi antar personal. Petugas kesehatan juga bisa lebih memahami persoalan atau kendala yang dihadapi Ibu-Ibu kader dalam melaksanakan program kesehatan.

Seringkali Ibu-Ibu kader Posyandu/PKK sudah mendapat pesan kesehatan, namun belum bisa melaksanakan program kesehatan itu. Misalnya Ibu-Ibu kader dan masyarakat di desa Bakalan (Bojonegoro) sudah mengetahui arti penting jamban sehat, namun terkendala biaya untuk membuatnya.

\section{Komunikasi Kelompok}

Komunikasi kelompok di kalangan penduduk, terutama Bapak-Bapak, lebih banyak terjadi di sawah/ tambak dan juga di warung kopi. Sebagian besar penduduk di daerah Gresik, para Bapak lebih suka ngobrol dan cangkruk di warung kopi. Sebagian besar harinya sudah digunakan untuk bekerja di sawah/tambak. Sehingga Bapak-Bapak menggunakan waktu sore atau malam untuk ngobrol/cangkruk di warung kopi. Petugas Puskesmas menggunakan momen ini untuk menemui Bapak-Bapak di warung kopi, kemudian menyisipkan obrolan tentang pesan kesehatan.

Petugas Puskesmas lebih banyak menggunakan kegiatan Posyandu dan PKK untuk melakukan komunikasi kelompok dengan Ibu-Ibu. Selain PKK dan Posyandu, kelompok yang terlibat dalam komunikasi kesehatan ini adalah Unit Kesehatan Sekolah (UKS). UKS didirikan di sekolah-sekolah, karena di Desa maka UKS didirikan di Sekolah Dasar (SD). Pesan komunikasi kesehatan yang disampaikan petugas adalah CTPS, 
karena sasarannya lebih banyak ke anak-anak. Namun program CTPS ini terkendala oleh fasilitas, misalnya pengadaan wastafel, sabun, serbet dan saluran air.

Dinkes juga mendekati pemuka/tokoh masyarakat dalam melakukan komunikasi kelompok. Opinion leader ini sering memudahkan Dinkes dalam menyampaikan pesan komunikasi kesehatan, karena pengaruh sosial budaya yang dimiliki oleh opinion leader tersebut. Sehingga masyarakat lebih mudah menerima pesan kesehatan Dinkes dan Puskesmas. Komunikasi kelompok yang dihadiri oleh Bapak-Bapak dan Ibu-Ibu adalah pada saat diadakan pengajian, tahlilan, yasinan dan istighasah. Pola komunikasi kelompok dapat digambarkan dalam bagan berikut:

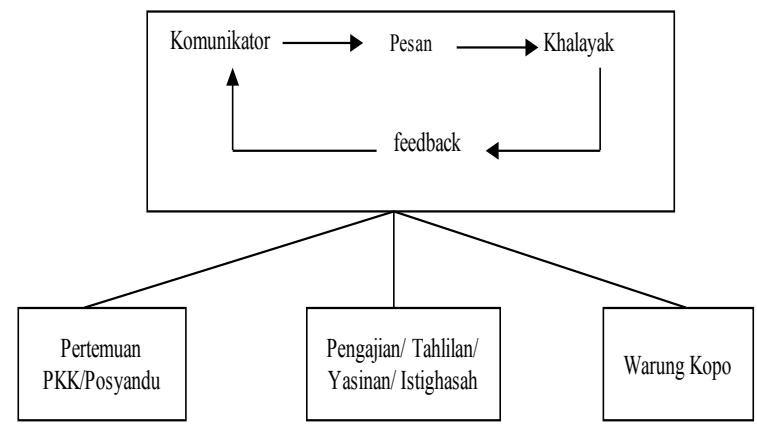

Gambar 2. Pola Komunikasi Kelompok

Kohesivitas kelompok yang terbentuk dalam PKK/Posyandu terutama terjadi diantara para pengurus atau kader. Kohesivitas ini terbentuk karena hampir semua kegiatan yang ada di Desa melalui kelompok ini. PKK selain melaksanakan program kesehatan, juga melakukan kegiatan sosial ekonomi lain, misalnya program PNPM (Program Nasional Pemberdayaan Masyarakat).

Kelompok PKK/Posyandu menjadi lebih kohesiv karena masing-masing anggota sering dan secara teratur bertemu untuk merencanakan dan melaksanakan berbagai kegiatan di Desa. Kegiatan rutin yang hampir tiap PKK mengadakan adalah arisan.

Berbagai kegiatan ini lama kelamaan membentuk kohesivitas diantara Ibu-Ibu. Semakin tinggi kohesivitas kelompok Ibu-Ibu, maka semakin tinggi pula tekanan kelompok pada masing-masing anggotanya. Misalnya tiap Ibu-Ibu di Desa hampir pasti menjadi anggota kelompok arisan PKK.

Demikian juga kelompok Bapak-Bapak yang sering bertemu dan ngobrol di warung kopi. Kohesivitas mereka terbentuk karena rutinitas pertemuan di warung kopi. Seperti yang sudah dijelaskan sebelumnya, kelompok Bapak-Bapak di warung kopi banyak ditemui di Desa Ngujungrejo (Gresik).

Kohesivitas yang terbentuk dalam kelompok pengajian, tahlilan dan yasinan terkait dengan kepercayaan dan norma agama. Kohesivitas ini terbentuk melalui ceramah agama yang biasanya dilaksanakan di mesjid, pembacaan surat Yasin dalam al Qur'an dan pembacaan tahlil dalam berbagai momen sosial budaya.
Kelompok pengajian, tahlilan dan yasinan adalah kelompok Bapak-Bapak yang lebih kohesiv dibanding kelompok di warung kopi. Kelompok pengajian ini memiliki tekanan yang lebih besar ke anggotanya dibanding kelompok di warung kopi. Mengingat kelompok ini terbentuk karena kesamaan keyakinan, nilai dan agama.

Dinkes telah menggunakan kelompok BapakBapak di warung kopi untuk menyampaikan pesan kesehatan. Dinkes juga sesekali mendekati ustadz atau kyai (opinion leader) untuk menyampaikan pesan kesehatan melalui kelompok pengajian. Salah satu Dinkes yang melakukan ini adalah Kabupaten Gresik.

\section{Komunikasi Massa}

Media yang sudah digunakan oleh Dinkes Gresik adalah Radio Komunitas Pemerintah Daerah (RKPD), acara ini dikemas dalam bentuk dialog interaktif. Dinkes memberikan materi kesehatan dalam tayangan acara kemudian dilanjutkan dengan tanya jawab dengan audiens. Namun radio ini sekarang sudah tidak beroperasi, kemudian dilanjutkan ke sebuah radio swasta (Suara Giri FM). Format acara masih tetap sama seperti di RKPD.

Dinkes juga menggunakan media cetak seperti poster, brosur, pamflet, leaflet dan buku. Media tradisional juga digunakan yaitu ludruk dan tayub. Dinkes mendesain tema acara/lakon tentang pesan kesehatan, kemudian dalang/aktor ludruk dan tayub menerjemahkan tema kesehatan tersebut dalam dialog dan lakon. Ludruk dan tayub ini digemari masyarakat karena media tradisonal ini dekat dengan rakyat dan hidup di tengah-tengah lingkungan sosial budaya mereka. Pola komunikasi massa dapat digambarkan dalam bagan berikut:

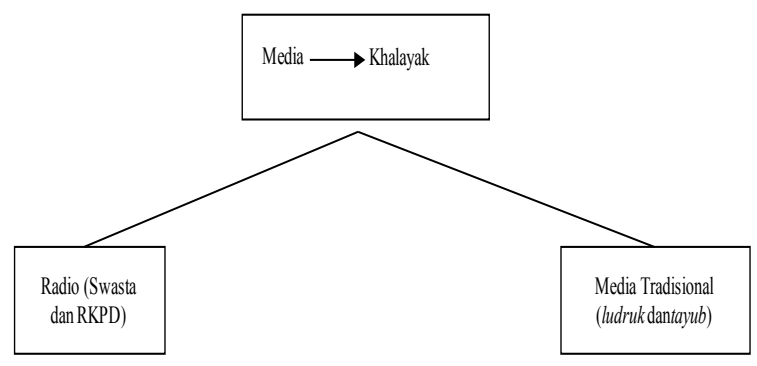

Gambar 3. Pola Komunikasi Massa

Media adalah alat yang mendominasi lingkungan simbolik masyarakat. Media akan sangat cepat menyampaikan pesan kesehatan ke masyarakat. Media sanggup memproduksi dan mendistribusi pesan kesehatan dalam waktu cepat dan masif.

Radio adalah media yang digunakan untuk menyampaikan pesan kesehatan ke masyarakat. Selain itu juga ada media tradisional ludruk dan tayub. Radio sanggup memproduksi dan mendistribusi pesan secara cepat ke masyarakat.

RKPD dan Suara Giri FM yang digunakan Dinkes Gresik untuk menyampaikan pesan kesehatan, 
telah mengkultivasi masyarakat. Setidaknya pesan kesehatan pernah menjadi bagian lingkungan simbolik masyarakat.

Demikian juga media tradisional ludruk dan tayub. Seperti halnya media tradisional lainnya, media ini memiliki tempat khas di hati masyarakat desa. Media ini, dengan aktor, lakon dan bahasa yang dekat dengan masyarakat, telah mendominasi ruang simbolik masyarakat.

Pesan media tradisional ini lebih mudah sampai ke masyarakat dibanding media radio. Pesan kesehatan melalui radio membutuhkan pesawat radio. Pesan kesehatan yang disampaikan melalui media tradisional tidak membutuhkan alat/perangkat untuk menerimanya. Masyarakat bisa langsung menyaksikan pertunjukan ludruk dan tayub di lapangan atau halaman balai desa atau tempat pertunjukannya.

\section{SIMPULAN}

Dinkes dan Puskesmas bisa menggunakan pola komunikasi secara terpisah, tapi bisa juga semua pola komunikasi diintegrasikan untuk menyampaikan pesan kesehatan (jamban/kakus, kesehatan lingkungan, air bersih, bahaya rokok, kesehatan ibu dan anak, edukasi gizi, penyakit menular, cuci tangan pakai sabun (CTPS) dan program kesehatan lainnya). Masing-masing pola komunikasi kesehatan memiliki karakter komunikan berbeda.

Komunikan dalam pola komunikasi antar personal lebih banyak Ibu-Ibu karena Bapak-Bapak tidak ada di rumah dan tidak terlibat dalam kegiatan PKK dan Posyandu. Pola komunikasi kelompok yang ada di warung kopi, semua khalayak adalah Bapak-Bapak. Khalayak komunikasi kelompok yang terdiri dari Bapak dan Ibu ada pada pola komunikasi kelompok di pengajian dan istighasah. Media cetak lebih banyak diterima dan dibaca oleh Ibu-Ibu.

\section{UCAPAN TERIMA KASIH}

Penulis mengucapkan terimakasih kepada DP2M DIKTI yang telah membiayai penelitian ini melalui skema penelitian strategis nasional (Stranas).

\section{DAFTAR PUSTAKA}

Denzin, Norman K., \& Lincoln, Yvonna S. 2000. Handbook of qualitative research. California. USA: Thousand Oaks.

Griffin, EM. 2006. A first look at communication theory. Sixth Edition. New York. USA: McGraw-Hill.

Liliweri, Alo. Prof.Dr. 2009. Dasar-dasar komunikasi kesehatan. Yogayakarta: Pustaka Pelajar.

Lindlof, Thomas R. 1995. Qualitative communication research methods. USA: SAGE Publications.

Littlejohn, Stephen W. and Karen Foss. 2008. Theories of human communication. Ninth Edition. USA: Thomson Wadsworth.

Malhotra, Naresh K. 1999. Marketing research: An applied orientation. Third Edition. USA: Prentice Hall.

McQuail, Denis. 2000. McQuail's Mass communication theory. $4^{\text {th }}$ Edition. California. USA: SAGE Publications.

McQuail, Denis. 2002. McQuail's reader in mass communication theory. California. USA: SAGE Publications.

Neuman, William Lawrence. 2000. Social research methods: Qualitative and quantitative approaches. USA: Allyn and Bacon.

Patton, Michael Quinn. 2002. Qualitative research and evaluation methods. $3^{\text {rd }}$ edition. California: SAGE Publications, Inc.

Monthly Report. 2010. Activity progress community based total sanitation, development of sanitation community access. Water and Sanitation Program-World Bank (WSP-World Bank). 